УДК 347.4

DOI: $10.17223 / 22253513 / 28 / 12$

\title{
О.С. Груздев
}

\section{ПРОИЗВОДНЫЙ ФИНАНСОВЫЙ ИНСТРУМЕНТ В СИСТЕМЕ ГРАЖДАНСКО-ПРАВОВЫХ ДОГОВОРОВ}

\begin{abstract}
Анализируется возможность квалификачии производного финансового инструмента в качестве самостоятельного договорного типа. Исследуются выделяемые в литературе признаки деривативов: производный характер стоимости дериватива от базисного актива, направленность на хеджсиование или спекуляцию, рисковость, срочность. Сделан вывод, что ни один из указанных признаков не может рассматриваться в качестве признака, квалифицирующего дериватив как самостоятельный договорной тип.

Ключевые слова: производный финансовый инструмент, договорный тип, направленность, хеджсирование, производность.
\end{abstract}

В отечественной правовой литературе производные финансовые инструменты рассматриваются в качестве некой родовой конструкции, признаки которой находят отражение в таких разновидностях, как фьючерсы, опционы, форварды и свопы [1. С. 23]. Вместе с тем комплексного правового анализа дериватива с точки зрения системы гражданско-правовых договоров не приводится. Разрешение поставленного вопроса представляется возможным посредством анализа системных признаков производных финансовых инструментов, позволяющих индивидуализировать их на фоне иных договоров, поименованных в ГК РФ.

Представляется, что анализ системы деривативов должен производится с учетом существующих позиций относительно построения системы гражданско-правовых договоров. Среди имеющихся подходов [2. С. 65; 3. С. 66], [4. С. 42] представляется верным подход Ю.В. Романца, относящегося к числу исследователей, которые в качестве основания для построения системы договоров усматривают как юридические, так и экономические признаки [5. С. 30-31; 6. С. 40-41; 7. С. 24; 8. С. 25]. Исследователь справедливо отмечает, что научно обоснованная система договоров должна формироваться по следующим критериям: во-первых, в качестве системных признаков должны рассматриваться особенности самих общественных отношений; во-вторых, системными могут быть не любые признаки отношений, а лишь значимые для права, вне зависимости от того, являются ли они юридическими или экономическими. Ю.В. Романец выделяет следующие структурные элементы системы гражданско-правовых договоров: договорный тип, вид и подвид [8. С. 26].

Авторы, занимающиеся исследованием правовой природы деривативов, выделяют у них следующие признаки: зависимость стоимости дериватива от стоимости базисного актива (производный характер), направленность 
дериватива на хеджирование и спекуляцию, рисковый характер дериватива, отсроченный характер исполнения обязательства [9. С. 22; 10. С. 26-29; 11. C. $14-17 ; 12$. C. $1157-1166 ; 13$. C. $18 ; 14$. C. $10 ; 15$. C. 181].

\section{Производный характер стоимости дериватива от стоимости базисного актива}

Практически всеми вышеуказанными исследователями отмечается, что в зависимости от роста или снижения стоимости базисного актива или изменения его показателей меняется стоимость и самого дериватива. Вместе с тем такой подход представляется в корне неверным.

Стоимость может отражать, с одной стороны, затраченные на производство некого объекта средства и усилия (т.е. себестоимость), с другой стороны, меновые свойства такого объекта. В таком случае оценивается эквивалент, за который объект может быть реализован. С точки зрения стоимостного подхода могут быть оценены товары, ценные бумаги, валюта, т.е. объекты, участвующие в обороте, но не события, такие как неплатеж по облигациям, введение в отношении должника процедуры банкротства и иные. Последние, в частности, являются кредитными событиями и выступают в качестве базисных активов для некоторых видов кредитных деривативов. Кроме того, деривативы представляют собой договоры и сами по себе не подлежат стоимостной оценке. Оценить можно лишь объем требований, возникающих в результате наступления внешних условий.

Таким образом, в юридическом смысле некорректно говорить о существовании «стоимости дериватива», т.е. с позиции права никакой зависимости стоимости дериватива от стоимости базисного актива нет, речь идет лишь о зависимости показателей дериватива от базисного актива. Причем такая зависимость имеет различное проявление в разных видах деривативов. В одних случаях наступление события, являющегося базисным активом, влечет наступление правового эффекта в виде обязанности выкупить некий товар или ценные бумаги. В других случаях изменение показателей базисного актива влечет возникновение обязанности по уплате денежных средств. В третьих случаях никаких правовых последствий изменение показателей базисного актива не влечет, а меняется лишь экономическая характеристика отношений цены базисного актива, зафиксированной в договоре и сложившейся на рынке.

В экономическом смысле стоимость дериватива может быть представлена в следующем. Так, вне зависимости от того, является ли форвардный договор поставочным или расчетным, его стоимость определяется посредством установления разницы между показателем базисного актива, сложившегося на рынке, и тем, что зафиксирован в договоре [16. С. 176-177]. Подобным же образом определяются показатели фьючерсов и опционов с учетом особенностей, присущих данным договорам. В частности, поскольку фьючерс заключается на бирже, его стоимость может быть установлена в рамках клиринга в каждый конкретный промежуток времени, 
тогда как стоимость форвардного договора определяется на дату его исполнения. В опционе, в отличие от других деривативов, право требовать исполнения предоставлено лишь одной из сторон, ввиду чего его стоимость не принимает отрицательных значений, т.е. колеблется в интервале от нуля до плюсовых значений. К тому же на рыночную стоимость опциона оказывает влияние вероятность наступления потенциального исполнения [17. С. 8 ; 18. С. 743].

Стоимость деривативов, исполнение по которым обусловлено двумя базисными активами, как, например, процентный, валютный, валютнопроцентный свопы, определяется с учетом значений разницы двух базисных активов [16. С. 243-244]. Стоимость же кредитно-дефолтных свопов зависит не от рыночной стоимости товара, валют или ценных бумаг, а от оценки вероятности наступления кредитного события, являющегося базисным активом, и определяется путем установления размера платежей, уплачиваемых за предоставление защиты от наступления кредитного события, с учетом вероятности его наступления [Там же. С. 697-700].

Таким образом, в зависимости от колебаний показателей базисного актива стоимость производного финансового инструмента (за исключением опциона) может принимать как отрицательное, так и положительное значение. Данное сугубо экономическое свойство приобретает правовое значение лишь в расчетных деривативах, но не поставочных.

В частности, если в расчетном производном финансовом инструменте изменение показателей базисного актива оказывает непосредственное влияние на правовое положение сторон договора, распределяя между ними права и обязанности, то при поставочных деривативах, предусматривающих поставку базисного актива, изменение его показателей не оказывает никакого влияния на характер распределения прав и обязанностей, так как является лишь экономической характеристикой заключенного между сторонами договора. Так, вне зависимости от изменения показателей базисного актива одна сторона обязана его поставить, а другая - оплатить по цене, согласованной в договоре, тогда как рост или падение показателей базисного актива в расчетном деривативе будет приводить к возникновению обязанности платить то у одной стороны, то у другой.

Исключением из приведенного правила являются поставочные деривативы, базисным активом которых является не товар, валюты или ценные бумаги, подлежащие передаче, а некие события или обстоятельства. Например, поставочные дефолтные свопы, базисным активом которых является условие (например неплатеж по облигации), при наступлении которого одна сторона обязуется поставить другой стороне товар (облигации, акции) по заранее согласованной цене. В таком случае вероятность наступления условия будет влиять на размер периодичного платежа, который подлежит уплате покупателем защиты по кредитно-дефолтному свопу.

Таким образом, то, что именуется производным характером стоимости дериватива от стоимости базисного актива, в действительности отражает следующее: 
1) характер распределения прав и обязанностей сторон договора, оказывающий влияние на статус кредитора или должника в обязательстве;

2) соотношение стоимости базисного актива, зафиксированного в договоре, и стоимости, сложившейся на рынке, но не оказывающее влияние на характер распределения прав и обязанностей сторон договора в рамках деривативов, предусматривающих поставку базисного актива;

3) размер периодичного платежа, уплачиваемого в рамках дериватива, базисным активом которого является условие.

\section{Направленность производного финансового инструмента}

Как отмечает Ю.В. Романец, под направленностью договора как системным признаком следует понимать конечные экономический и юридический результаты, на достижение которых направлены основные действия участников договора [8. С. 92]. Направленность договора отражает цель, которую преследуют стороны договора при его заключении. Именно по данному критерию выделяются такие договорные типы, как договоры, направленные на передачу имущества в собственность, оказание услуг, на осуществление работ, страхование и т.д. По мнению других исследователей, данный критерий следует именовать каузой (основанием) договора [19. С. 101].

В юридической литературе традиционно отмечается, что производный финансовый инструмент направлен на хеджирование рисков, под которым понимается страховка от наступления неблагоприятных последствий [20. C. $231 ; 21$. C. $43 ; 22$. C. $89-90 ; 23$. C. 43-46].

К числу наиболее ярких примеров хеджирования можно отнести пример использования процентного свопа, нашедшего, наравне с опционами, широкое отражение в судебной практике по налоговым спорам [24, 25], [26], когда одно лицо - должник по договору займа, опасаясь роста плавающих процентных ставок, договаривается с другим лицом - контрагентом по процентному свопу, что контрагент будет платить плавающую процентную ставку, а первоначальное лицо (должник по договору займа) будет платить ему фиксированную ставку. В зависимости от роста или падения плавающей ставки стороны будут уплачивать разницу, рассчитанную относительно некой номинальной суммы. Таким образом, должник по договору займа переложил риск роста плавающих процентных ставок на контрагента по процентному свопу.

Представляется, что позиция исследователей, рассматривающих хеджирование и спекуляцию в качестве направленности всех производных финансовых инструментов, является ошибочной. Так, направленность договора рассматривается в качестве обозримой хозяйственной цели сторон, которая преследуется при заключении договора. Поскольку договор есть сделка, которая в свою очередь, представляет собой волевое действие, цель договора есть направленность воли сторон, т.е. тот экономический и правовой результат, который преследуют стороны при заключении договора. 
Действительно, в той терминологии, которая вкладывается в понятие «хеджирование», на первый взгляд, применительно к отдельным видам производных финансовых инструментов можно предположить, что хеджирование составляет направленность сторон при использовании деривативов. Вместе с тем в большинстве случаев эта цель не относится к числу юридически значимых.

Так, в вышеприведенном примере стороны заключили между собой процентный своп-договор, по условиям которого одна сторона платит фиксированную ставку, а другая сторона - плавающую ставку. Плательщик фиксированной ставки страхует свои риски по договору займа, связанные с ростом плавающих ставок. Плательщик плавающей ставки по процентному свопу не преследует целей страхования рисков, а заинтересован лишь в том, чтобы получить прибыль в виде разницы от ценовых колебаний.

По сути, конечная цель обоих сторон состоит лишь в том, чтобы получить разницу, сложившуюся в результате колебаний значений базисного актива. Обозримая цель каждой из сторон состоит в том, чтобы получить от контрагента платеж, обусловленный изменениями конъюнктуры рынка. В свою очередь, то, что интерес одной из сторон состоит в минимизации расходов по договору займа, а другой стороны - в получении прибыли, является лишь мотивом при заключении договора, но не самостоятельной правовой или экономической целью. В таком случае деривативы, опосредующие взаиморасчеты между сторонами, в зависимости от роста или падения значений базисных активов направлены не на хеджирование или спекуляцию, а на получение от другой стороны платежей, поставленных в зависимость от колебаний значений базисного актива.

Исключением из вышеуказанного подхода могут быть лишь опционы, в которых право требовать исполнения обусловлено внешним условием, и дефолтные свопы в тех случаях, если наступление условия (кредитное событие в кредитно-дефолтных свопах) в сделке может оказать влияние на имущественное состояние управомоченного лица. В таком случае приведенные виды деривативов действительно направлены на перераспределение рисков наступления неблагоприятных последствий, поскольку исполнение по таким деривативам всегда будет зависеть от некого внешнего фактора, наступление которого не гарантировано. Сторона - покупатель защиты, принимая на себя обязанность вносить периодичные платежи за предоставление другой стороной защиты, не имеет иной цели, кроме как обеспечить перераспределение рисков наступления последствий.

Аналогичные выводы следуют в отношении поставочных деривативов, опосредующих передачу товаров, валют, ценных бумаг. Например, стороны договариваются, что одна сторона поставит другой стороне акции по заранее согласованной цене через шесть месяцев. В таком случае, зафиксировав цену исполнения, каждая из сторон захеджировала свои риски от, соответственно, роста или падения стоимости ценных бумаг. Вместе с тем при таком подходе игнорируется, что основная цель сторон поставочного дериватива заключается в поставке имущества в обмен на деньги, что 
в значительной степени сближает данную разновидность деривативов с договорами, направленными на передачу имущества в собственность.

Направленность на спекуляцию, применительно к деривативам, может быть выделена весьма условно. Спекулятивный интерес стороны просматривается лишь в том случае, если выходить за рамки правоотношений сторон дериватива, например покупатель ценных бумаг преследует цель, купив их дешевле по отношению к рынку, продать по рыночной цене. Однако и в данном случае интерес в проведении спекулятивной сделки лежит за рамками воли сторон при заключении дериватива, он представляет собой мотив.

Таким образом, спекуляция не может рассматриваться в качестве направленности сделок, являющихся производными финансовыми инструментами. Если хеджирование рассматривать как направленность на распределение рисков, то оно свойственно лишь некоторым видам опционов и дефолтных свопов. Во всех остальных случаях хеджирование следует относить к мотиву сделки. В связи с чем все деривативы могут быть классифицированы по направленности:

1) получение от контрагента платежей, поставленных в зависимость от изменения показателей базисного актива;

2) передачу имущества в собственность в обмен на деньги;

3) распределение рисков наступления неблагоприятных последствий (хеджирование);

4) заключение другого договора. Направленность воли сторон на заключение другого договора нашла свое отражение в положениях абз. 4 п. 2, абз. 3 п. 3, п. 5 указания Банка России «О видах производных финансовых инструментов» [27]. В частности, условия некоторых деривативов могут предусматривать заключение договоров купли-продажи либо договоров, являющихся производными финансовыми инструментами, как, например, свопционы (опционы на заключение свопов). При этом исполнение такой обязанности, как правило, также поставлено в зависимости от некоторого условия.

\section{Рисковый характер производных финансовых инструментов}

Правовой природе рисковых сделок в юридической литературе уделяется достаточно много внимания. Представляется, что под такими сделками следует понимать, во-первых, сделки, которые не позволяют определить объем и характер исполнения на стадии ее заключения [28. С. 25, 523; 29. С. $32 ; 30$. С. 173-174; 31. С. 11-13], а во-вторых, такие сделки относятся к числу условных [32. С. 780; 33. С. $154 ; 34$. С. 64; 35. С. 155; 36. С. 45].

Не все виды производных финансовых инструментов могут быть отнесены к числу рисковых сделок, а лишь те, в которых права и обязанности сторон зависят от наступления согласованных сторонами условий. В таком случае к числу рисковых не будут относиться большинство видов поставочных деривативов, за исключением поставочных опционов и некоторых 
дефолтных своп-договоров, предусматривающих расчет поставкой. В частности, по условиям опциона одна сторона, уплачивая другой стороне некоторую сумму денежных средств, получает право требовать от нее исполнения. Причем наличие такого права может быть поставлено под самостоятельное внешнее условие, как, например, изменение значений базисного актива выше или ниже согласованных значений. Другая же сторона по требованию управомоченной обязуется произвести исполнение на условиях, согласованных сторонами. При этом исполнение будет производиться и в том случае, если условия исполнения окажутся невыгодными для обязанной стороны. Схожие выводы могут быть сделаны в отношении дефолтных свопов.

Таким образом, деривативы, предусматривающие лишь отсроченную поставку, лишенные случайного элемента, влияющего на распределение прав и обязанностей, не могут быть отнесены к числу рисковых сделок. В то же время поставочные деривативы, исполнение которых зависит от наступления обстоятельств, носящих случайный характер, могут быть отнесены к числу рисковых сделок.

В силу своей экономической природы все производные финансовые инструменты, предусматривающие взаиморасчеты между сторонами, могут быть отнесены к числу рисковых сделок, поскольку в таких сделках предусматривается, что в зависимости от изменения значений базисного актива стороны договора уплачивают друг другу денежные средства. Иными словами, изменение значений базисного актива будет свидетельствовать об изменении правового положения сторон договора. В таком случае в каждый конкретный промежуток времени, в который одна сторона приобретает право требования от другой стороны уплаты денежных средств, такая сторона будет становиться кредитором в денежном обязательстве, а другая сторона - должником. После чего, в зависимости от изменения показателей базисного актива, статус сторон договора будет меняться (и так до истечения срока действия договора).

\section{Отсроченный характер исполнения от момента заключения производного финансового инструмента}

Деривативы также именуются срочными сделками. Отмечается, что в отличие от кассовых сделок срочные сделки всегда предполагают значительный промежуток времени между заключением сделки и ее исполнением [37. С. 51-52]. Например, в указании Банка России «О видах производных финансовых инструментов» [27] отмечается, что по условиям поставочного форвардного договора предусматривается отсрочка поставки на срок не менее трех дней с момента заключения договора.

Названное свойство применимо ко всем видам деривативов, поскольку вне зависимости от того, является ли дериватив свопом, фьючерсом, опционом или форвардом, момент его исполнения всегда отсрочен от момента заключения такого договора. Вместе с тем представляется, что данное 
свойство деривативов также не может относиться к числу квалифицирующих по следующим причинам:

а) абсолютное большинство договоров, закрепленных в гражданском законодательстве, предусматривают исполнение по истечении промежутка времени от момента их заключения;

б) данный признак никаким образом не отражает особенность правовой природы дериватива;

в) позиция Банка России в части установления трехдневного срока ничем не обусловлена и представляется следствием волевого решения регулятора финансового рынка.

Итак, по результатам проведенного анализа, ни один из приведенных признаков деривативов, которые выделяются в специальных исследованиях, не может быть отнесен к числу признаков, наличие которых позволило бы говорить именно о системе деривативов, объединенных в определенное единство. Поскольку не все признаки присущи каждой разновидности дериватива, да и те, которые можно выделить, не позволяют индивидуализировать и обособить деривативы от иных договоров. Данное обстоятельство свидетельствует о том, что деривативы не имеют признаков, позволяющих отнести их к самостоятельному договорному типу, и, соответственно, их правовая квалификация должна производиться с точки зрения других договоров, известных гражданскому праву.

\section{Литература}

1. Овсейко С.В. Свопы: общая характеристика производного финансового инструмента // Юрист. 2012. № 24. С. 22-29.

2. Аскназий С.И. Очерки хозяйственного права СССР / Коммунистический университет им. Зиновьева. Л. : Рабочее изд-во «Прибой», 1926. 200 с.

3. Гордон М.В. Система договоров в советском гражданском праве // Ученые записки / Харьковский юридический институт им. Л.М. Кагановича. Кафедра гражданского права и процесса. Харьков : Изд-во Харьков. гос. ун-та им. А.М. Горького, 1954. Вып. 5. С. 65-87.

4. Красавчиков О.А. Система отдельных видов обязательств // Советская юстиция. 1960. № 5. С. 42-43.

5. Брагинский М.И. Общее учение о хозяйственных договорах. Минск : Наука и техника, 1967. 260 с.

6. Егоров Н.Д. Классификация обязательств по советскому гражданскому праву // Советское государство и право. 1989. № 3. С. 40-41.

7. Иоффе О.С. Избранные труды по гражданскому праву. М. : Статуг, 2000. 781 с.

8. Романеи Ю.В. Система договоров в гражданском праве России. 2-е изд., перераб. и доп. М. : Норма, Инфра-М, 2013. 496 с.

9. Буркова А.Ю. Виды производных финансовых инструментов и их защита в России // Законодательство и экономика. 2010. № 6. С. 21-24.

10. Ротко С.В. Судьба производных финансовых инструментов, возможно, определена? // Налоги. 2010. № 16. С. 26-29.

11. Балкаров А.Б. Юридическая квалификация производных финансовых инструментов (деривативов или срочных сделок) // Налоги. 2011. № 5. С. 14-17.

12. Греков М.Н. Проблемы правовой квалификации деривативного обязательства // Актуальные проблемы российского права. 2014. № 6. С. 1157-1166. 
13. Жуков Д.А. Правовое регулирование срочных сделок на фондовом рынке : автореф. дис. ... канд. юрид. наук. М., 2007. 25 с.

14. Туктаров Ю.Е. Синтетическая секьюритизация // Секьюритизация и право / Жан Жоб де Вриз Роббе, Поль Али ; пер. с англ. М. : Волтерс Клувер, 2008. 600 с.

15. Селивановский А.С. Правовое регулирование рынка ценных бумаг. М. : Издательский дом Высшей школы экономики, 2014. 580 с.

16. Халл Дж.К. Опционы, фьючерсы и другие производные финансовые инструменты. Москва ; Санкт_Петербург ; Киев : Вильямс, 2014. 1070 с.

17. Овечкин Р.M., Финогеев А.Г. Модели и методы оценки стоимости и подразумеваемой волатильности // Известия высших учебных заведений. Поволжский регион. Технические науки. 2013. № 3 (27). С. 5-15.

18. Фабоции Ф. Финансовые инструменты. М. : Эксмо, 2010. 864 с.

19. Кашанин A.B. Кауза гражданско-правового договора, как выражение его сущности // Журнал российского права. 2001. № 4. С. 93-104.

20. Белов B.A. Понятие и виды торговых договоров. Курс лекций : учебное пособие для бакалавриата и магистратуры. М. : Юрайт, 2017. 502 с.

21. Буркова А.Ю. Трудности перехода на централизованный клиринг // Право и экономика. 2017. № 2. С. 41-44.

22. Бартош В. Хеджирование и сделки на разницу цены базового актива // Хозяйство и право. 2012. № 9. С. 85-93.

23. Долганин A.A. К вопросу о понятии хеджирования в российской правовой доктрине // Гражданское право. 2016. № 6. С. 43-46.

24. Постановление Президиума ВАС РФ от 26.06.2012 № 15740/11 по делу № А2810038/2010-281/33 // Консультант Плюс : Справ.-правовая система. Судебная практика. Электрон. дан. М., 2013. Доступ из локальной сети Науч. б-ки Том. гос. ун-та.

25. Постановление ФАС Волго-Вятского округа от 16.06.2008 по делу № А4311550/2005-35-399 // Консультант Плюс : Справ.-правовая система. Судебная практика. Электрон. дан. М., 2013. Доступ из локальной сети Науч. б-ки Том. гос. ун-та.

26. Постановление ФАС Московского округа от 19.05.2010 № КА-А40/2599-10 по делу № А40-77534/09-142-442 // Консультант Плюс : Справ.-правовая система. Судебная практика. Электрон. дан. М., 2013. Доступ из локальной сети Науч. б-ки Том. гос. ун-та.

27. O видах производных финансовых инструментов: Указание Банка России от 16.02.2015 № 3565-У // Консультант Плюс : Справ.-правовая система. Версия Проф. Электрон. дан. М., 2015. Доступ из локальной сети Науч. б-ки Том. гос. ун-та.

28. Победоносиев К.П. Курс гражданского права. Часть третья: Договоры и обязательства. М. : Статут, 2003. 622 c.

29. Годэмэ Е. Общая теория обязательств. М. : Юрид. изд-во Мин. юстиции СССР, $1948.511 \mathrm{c}$.

30. Виншейд Б. Об обязательствах по римскому праву. СПб., 1875. 593 с.

31. Мадагаева Т.Ф. Правовая природа рискового договора // Юрист. 2012. № 18. C. $11-13$.

32. Гамбаров Ю.Г. Гражданское право. Общая часть / под ред. В.А. Томсинова. М. : Зерцало, 2003. $816 \mathrm{c}$.

33. Гримм Д.Д. Лекции по догме римского права. М. : Зерцало, 2003. 496 с.

34. Нерсесов Н.O. Понятие добровольного представительства в гражданском праве // Избранные труды по представительству и ценным бумагам в гражданском праве. М. : Типолит. И.И. Смирнова, 1998. $191 \mathrm{c.}$

35. Синайский В.И. Русское гражданское право. М. : Статут, 2002. 638 с.

36. Новиикий И.Б. Сделки. Исковая давность. М. : Госюриздат, 1954. 247 с.

37. Авилина И.В., Козырь О.М. Биржа: правовые основы организации и деятельности. М. : Экономика и право, 1991.93 с. 
Gruzdev Oles S., Tomsk State University (Tomsk, Russian Federation)

DERIVATIVE FINANCIAL INSTRUMENT IN THE SYSTEM OF CIVIL CONTRACTS

Keywords: derivative financial instrument, contractual type, orientation, hedging, derivativeness.

DOI: $10.17223 / 22253513 / 28 / 12$

The subject to be analyzed in the present article is the possibility of qualification of a derivative financial instrument as a separate contractual type. The objectives of the research are examination of the existing approaches and the analysis of the characteristics of derivatives. The derivatives can differ from other financial instruments since they have the derived character of value from a basic asset, orientation at hedging or speculation; risk-taking and urgency.

In the course of the analysis the author comes to conclusion that any of the specified characteristics cannot be considered as the sign qualifying the derivative as an independent contractual type. Thus, a derived nature of value has legal sense only for non-deliverable and some deliverable derivative instruments, because of its influence on the allocation of rights and obligations of the parties to a contract. In the majority of deliverable derivatives this sign has no legal character since does not exert impact on the rights and obligations of the parties of the contract. Hedging can be considered as an orientation only in relation to default swaps or options in which the subjective right of the authorized person is put into dependence on a condition and this condition can cause negative consequences for the property status of the entitled party.

Otherwise, the derivative is aimed at making profit due to change of basic asset's indexes. Speculation represents a motive for the sake of which the parties can conclude the derivative, but it is not an independent legal purpose. Non-deliverable and conditional deliverable derivatives are aleatory but most of deliverable derivatives are not, because the parties know the type of their performance by the contract's conclusion. The maturity of contracts can't be the qualifying attribute since most of defined contracts also have this characteristic. A risk-related character of derivatives is shown only in non-deliverable derivative instruments and in those deliverable derivatives, the performance of which depends on a condition. Deliverable derivatives are, as a rule, deprived of a risk-related character since the volume and the parties know the nature of performance at the stage of the conclusion of such contract. An urgent character, being found in all types of derivatives, cannot act as the individualizing characteristic because it can be equally found in many contracts, which are named in the civil code.

The author comes to conclusion, that existing attributes either belong only to some derivatives or do not ascertain these financial instruments among other contractual constructions. Furthermore, some derivatives are similar to those enshrined in national civil legislation e.g. a wagering contract, contract of sale or barter.

\section{References}

1. Ovseyko, S.V. (2012) Svopy: obshchaya kharakteristika proizvodnogo finansovogo instrumenta [Swaps: a general characteristic of a derivative financial instrument]. Yurist - Jurist. 24. pp. 22-29.

2. Asknaziy, S.I. (1926) Ocherki khozyaystvennogo prava SSSR [Essays on the Economic Law of the USSR]. Leningrad: Priboy.

3. Gordon, M.V. (1954) Sistema dogovorov v sovetskom grazhdanskom prave [The system of treaties in Soviet civil law]. Uchenyye zapiski. Khar'kovskiy yuridicheskiy institut im. L.M. Kaganovicha. 5. pp. 65-87.

4. Krasavchikov, O.A. (1960) Sistema otdel'nykh vidov obyazatel'stv [The system of certain types of obligations]. Sovetskaya yustitsiya. 5. pp. 42-43. 
5. Braginskiy, M.I. (1967) Obshcheye ucheniye o khozyaystvennykh dogovorakh [General doctrine of economic contracts]. Minsk: Nauka i tekhnika.

6. Egorov, N.D. (1989) Klassifikatsiya obyazatel'stv po sovetskomu grazhdanskomu pravu [Classification of obligations under Soviet civil law]. Sovetskoye gosudarstvo i pravo. 3. pp. $40-41$.

7. Ioffe, O.S. (2000) Izbrannyye trudy po grazhdanskomu pravu [Selected Works on Civil Law]. Moscow: Statut.

8. Romanets, Yu.V. (2013) Sistema dogovorov v grazhdanskom prave Rossii [The System of Contracts in the Russian Civil Law]. 2nd ed. Moscow: Norma, Infra-M.

9. Burkova, A.Yu. (2010) Vidy proizvodnykh finansovykh instrumentov i ikh zashchita $\mathrm{v}$ Rossii [Types of derivatives and their protection in Russia]. Zakonodatel'stvo i ekonomika. 6. pp. 21-24.

10. Rotko, S.V. (2010) Sud'ba proizvodnykh finansovykh instrumentov, vozmozhno, opredelena? [The fate of derivative financial instruments may have been determined?]. Nalogi-Taxes. 16. pp. 26-29.

11. Balkarov, A.B. (2011) Yuridicheskaya kvalifikatsiya proizvodnykh finansovykh instrumentov (derivativov ili srochnykh sdelok) [Legal qualification of derivative financial instruments (derivatives or futures deals)]. Nalogi-Taxes. 5. pp. 14-17.

12. Grekov, M.N. (2014) Problemy pravovoy kvalifikatsii derivativnogo obyazatel'stva [Problems of legal qualification of the derivative obligation]. Aktual'nyye problemy rossiyskogo prava - Actual Problems of Russian Law. 6. pp. 1157-1166. DOI: 10.7256/19941471.2014.6.11530

13. Zhukov, D.A. (2007) Pravovoye regulirovaniye srochnykh sdelok na fondovom rynke [Legal regulation of futures transactions in the stock market]. Abstract of Law Cand. Diss. Moscow.

14. Tuktarov, Yu.E. (2008) Sinteticheskaya sek'yuritizatsiya [Synthetic Securitization]. In: Robbe, J.J.de V. \& Ali, P. Sek'yuritizatsiya i pravo [Securitisation of Derivatives and Alternative Asset Classes]. Translated from English by O. Ivanov, A. Kazakov, M. Shakhunyan. Moscow: Walters Kluwer.

15. Selivanovskiy, A.S. (2014) Pravovoye regulirovaniye rynka tsennykh bumag [Legal Regulation of the Securities Market]. Moscow: HSE.

16. Hull, J.K. (2014) Optsiony, f'yuchersy i drugiye proizvodnyye finansovyye instrument [Options, Futures, and Other Derivatives]. Translated from English by D. Klyushin. Moscow; St. Petersburg; Kyiv: Vil'yams.

17. Ovechkin, R.M. \& Finogeyev, A.G. (2013) Models and methods of option value assessment and the implied volatility. Izvestiya vysshikh uchebnykh zavedeniy. Povolzhskiy region. Tekhnicheskiye nauki - University proceedings. Volga Region. Technical Sciences. 3(27). pp. 5-15. (In Russian).

18. Fabozzi, F. (ed.) (2010) Finansovyye instrumenty [The Handbook of Financial Instruments]. Translated from English by E. Vostrikova, D. Kovalevsky, M. Orlov. Moscow: Eksmo.

19. Kashanin, A.V. (2001) Cause of civil law contract as an expression of its essence. Zhurnal rossiyskogo prava - Journal of Russian Law. 4. pp. 93-104. (In Russian).

20. Belov, V.A. (2017) Ponyatiye i vidy torgovykh dogovorov [The Concept and Types of Trade Agreements]. Moscow: Yurayt.

21. Burkova, A.Yu. (2017) Trudnosti perekhoda na tsentralizovannyy kliring [Difficulties of transition to centralized clearing]. Pravo i ekonomika. 2. pp. 41-44.

22. Bartosh, V. (2012) Khedzhirovaniye i sdelki na raznitsu tseny bazovogo aktiva [Hedging and transactions for the difference in the price of the underlying asset]. Khozyaystvo $i$ pravo - Business and Law. 9. pp. 85-93.

23. Dolganin, A.A. (2016) Revisiting the Hedging in the Russian Legal Doctrine. Grazhdanskoye pravo - Civil Law. 6. pp. 43-46. (In Russian). 
24. The Supreme Arbitration Court of the Russian Federation. (2013) Postanovleniye Prezidiuma VAS RF ot 26.06.2012 № 15740/11 po delu № A28-10038/2010-281/33 [Decree No. 15740/11 of the Presidium of the Supreme Arbitration Court of the Russian Federation of June 26, 2012, in case No. A28-10038 / 2010-281 / 33]. [Online] Available from: http://www.consultant.ru/cons/cgi/online.cgi?req=doc;base=ARB; $=293533 \# 0999159071861$ 1856.

25. The Federal Arbitration Court of Volgo-Vyatsky District. (2008) Postanovleniye FAS Volgo-Vyatskogo okruga ot 16.06.2008 po delu № A43-11550/2005-35-399 [Decree of the FAS of the Volga-Vyatka okrug of June 16, 2008, in case No. A43-11550 / 2005-35-399]. [Online] Available from: http://www.consultant.ru/cons/cgi/online.cgi?req= doc;base $=\mathrm{AVV} ; \mathrm{n}=28274 \# 0028855868518551375$.

26. The Federal Arbitration Court of Moscow District. (2010) Postanovleniye FAS Moskovskogo okruga ot 19.05.2010 № KA-A40/2599-10 po delu № A40-77534/09-142-442 [Decree of the Federal Arbitration Court of the Moscow District of May 19, 2010, No. KA-A40 / 2599-10 in case No. A40-77534 / 09-142-442]. [Online] Available from: http://www.consultant.ru/cons/cgi/online.cgi?req=doc;base=AMS;n=128127\#0921701173730 888.

27. The Bank of Russia. (2015) O vidakh proizvodnykh finansovykh instrumentov: Ukazaniye Banka Rossii ot 16.02.2015 № 3565-U [On the types of derivative financial instruments: Instruction № 3565-U of the Bank of Russia of February 16, 2015]. [Online] Available from: http://www.consultant.ru/document/cons_doc_LAW_177289/.

28. Pobedonostsev, K.P. (2003) Kurs grazhdanskogo prava [The Course of Civil Law]. Part 3. Moscow: Statut.

29. Godame, E. (1948) Obshchaya teoriya obyazatel'stv [General Theory of Obligations]. Translated from French by I.B. Novitsky. Moscow: Ministry of Justice of the USSR.

30. Winscheid, B. (1875) Ob obyazatel'stvakh po rimskomu pravu [About obligations under the Roman law]. Translated from German. St. Petersburg: A. Dumashevsky.

31. Madagayeva, T.F. (2012) Legal Nature of Risky Contract. Yurist - Jurist. 18. pp. 1113. (In Russian).

32. Gambarov, Yu.G. (2003) Grazhdanskoye pravo. Obshchaya chast' [Civil law. General Part]. Moscow: Zertsalo.

33. Grimm, D.D. (2003) Lektsii po dogme rimskogo prava [Lectures on the Dogma of Roman law]. Moscow: Zertsalo.

34. Nersesov, N.O. (1998) Izbrannyye trudy po predstavitel'stvu $i$ tsennym bumagam $v$ grazhdanskom prave [Selected Works on Representation and Securities in Civil Law]. Moscow: I.I. Smirnov.

35. Sinayskiy, V.I. (1954) Russkoye grazhdanskoye pravo [Russian Civil Law]. Moscow: Statut.

36. Novitskiy, I.B. (1954) Sdelki. Iskovaya davnost' [Transactions. Limitation of Actions]. Moscow: Gosyurizdat.

37. Avilina, I.V. \& Kozyr, O.M. (1991) Birzha: pravovyye osnovy organizatsii $i$ deyatel'nosti [Exchange House: Legal basis for organization and activities]. Moscow: Ekonomika i pravo. 